\title{
Preparation, Characterizaton and Catalytic Aerobic Oxidation by a Vanadium Phosphonate Mesoporous Material Constructed from a Dendritic Tetraphosphonate
}

\author{
Maxym Vasylyev and Ronny Neumann* \\ Weizmann Institute of Science, Dept. of Organic Chemistry, Rehovot, Israel 76100
}

\section{Experimental Section}

Materials and Methods. Vanadium(V) oxytriisopropoxide, diethylphosphite, triethylamine, anhydrous benzene and dichlorobis(triphenylphosphine)palladium (II) were obtained from Aldrich and used as received. DMSO anhydrous $\geq 99.9 \%$ grade was received from Aldrich and stored under $4 \AA$ molecular sieves before use. The ${ }^{1} \mathrm{H}$ NMR spectra were measured on a Bruker Avance 400 spectrometer at $400 \mathrm{MHz}$ in $\mathrm{CDCl}_{3}$ or DMSO- $d_{6}$ and the chemical shifts are reported as ppm relative to an internal tetramethylsilane standard. ${ }^{13} \mathrm{C}\left\{{ }^{1} \mathrm{H}\right\}$ NMR spectra were measured on a Bruker Avance 400 spectrometer at $100.6 \mathrm{MHz}$ in $\mathrm{CDCl}_{3}$ or $\mathrm{DMSO}-d_{6}$ solvents. ${ }^{31} \mathrm{P}$ NMR spectra were measured on a Bruker DPX 250 spectrometer at $101 \mathrm{MHz}$ in $\mathrm{CDCl}_{3}$ or DMSO- $d_{6}$ and the chemical shifts are reported as ppm relative to an external $85 \%$ phosphoric acid standard at $300 \mathrm{~K}$ with line broadening of $1 \mathrm{~Hz}$. The IR spectrum was measured on a Nicolet Protégé 460 with a sample deposited in the KBr pellet.

TEM and EDS Studies. A Philips CM-120 ST transmission electron microscope, operating at $120 \mathrm{kV}$, was used to observe the morphology of the material. Samples were prepared by dispersing the particles in ethyl alcohol by ultrasonic treatment and then dropping them onto a holey carbon film supported on a copper grid. The samples were stable under electron beam radiation. Energy dispersive spectrometry (EDS) analysis was carried out using an EDAX instrument (Phoenix) equipped with a $\mathrm{Si}(\mathrm{Li})$ retractable detector with a super ultra thin window. 
SEM Studies. A SUPRA 55 VP FEG LEO HR SEM with accelerating voltage of $1.0 \mathrm{kV}$ was used to observe the morphology of the material. Samples were prepared by dispersing the particles in ethyl alcohol by ultrasonic treatment and dropping them onto silicon slides.

$N_{2}$ Sorption Studies. Sorption experiments were carried out using Quantachrome NOVA 1000 high speed sorption analyzer. Data were analyzed (BET surface area calculation, BJH pore size distribution) using NOVAWin software. TPPhA-V hybrid material was degassed for $4 \mathrm{~h}$ at $100{ }^{\circ} \mathrm{C}$ prior measurement. Pore size calculation for determination of mesopore size distribution was conducted from the desorption branch of isotherm using Barrett-JoynerHalenda method taking in account data points above $0.35 \mathrm{PP}_{0}^{-1}$. Surface area calculated using five point nitrogen Brenauer-Emmet-Teller (BET) method.

XRD Measurements. X-ray powder diffraction patterns were measured in the $\theta / 2 \theta$ mode using a D-Max/B horizontal goniometer (Rigaku) affixed to a RU200 rotating anode X-ray generator $\left(12 \mathrm{~kW}\right.$, Rigaku) with $\mathrm{Cu}$ target $\left(\mathrm{Cu} \mathrm{K}_{\alpha}\right)$. The sample was dispersed on a background-free silicon sample holder.

Thermal Gravimetric Analysis: Thermal Gravimetric Analysis was carried out on Shimadzu DTG-50 analyzer.

\section{Synthesis.}

Tetrakis-1,3,5,7-(4-diethylphosphonatophenyl)adamantane. To an Ace Glass pressure tube containing a solution of tetrakis-1,3,5,7-(4-iodophenyl)adamantane $(1 \mathrm{~g}, 1 \mathrm{mmol})$ in dry benzene $(10 \mathrm{~mL})$, diethyl phosphate $(2.48 \mathrm{~mL}, 19.4 \mathrm{mmol})$, triethylamine $(5 \mathrm{~mL})$ and of dichlorobis(triphenylphosphine)palladium(II) $(0.02 \mathrm{~g}, 0.032 \mathrm{mmol})$ were added under an argon atmosphere. A stirring bar was added and the pressure tube was sealed. The mixture was heated at $80{ }^{\circ} \mathrm{C}$ for $72 \mathrm{~h}$ with stirring, and then cooled; the precipitated triethylammonium iodide was filtered off. The filtrate was concentrated by evaporation and the residual oil was diluted with cold water $(100 \mathrm{~mL})$. The precipitate obtained was filtered, washed twice with 
water and dried under high vacuum for $72 \mathrm{~h}$. This gave the tetrakis 1,3,5,7-(4diethylphosphonatophenyl)adamantane as a pale-yellow slightly hygroscopic solid (0.75 g, $76 \%$ ). The product was sufficiently pure enough to use without further purification. ${ }^{1} \mathrm{H}$ NMR $\left(400 \mathrm{MHz}, \mathrm{CDCl}_{3}\right): \delta=1.3(\mathrm{t}, J=7 \mathrm{~Hz}, 24 \mathrm{H}), 2.2(\mathrm{br} \mathrm{s}, 12 \mathrm{H}), 4.1(\mathrm{~m}, 16 \mathrm{H}), 7.6(\mathrm{~d}, J=4 \mathrm{~Hz}$, 8H), $7.8(\mathrm{~m}, 8 \mathrm{H}) \mathrm{ppm} ;{ }^{31} \mathrm{P}$ NMR $\left(101 \mathrm{MHz}, \mathrm{CDCl}_{3}\right): \delta=17.6$ (s) ppm; ${ }^{13} \mathrm{C}$ NMR $(100.6 \mathrm{MHz}$, $\left.\mathrm{CDCl}_{3}\right): \delta=16.26(\mathrm{~d}, J(\mathrm{C}, \mathrm{P})=7 \mathrm{~Hz}), 39.46,46.50,62.08(\mathrm{~d}, J(\mathrm{C}, \mathrm{P})=5 \mathrm{~Hz}), 125.12(\mathrm{~d}$, $J(\mathrm{C}, \mathrm{P})=15 \mathrm{~Hz}), 126.04(\mathrm{~d}, J(\mathrm{C}, \mathrm{P})=234 \mathrm{~Hz}), 132.06(\mathrm{~d}, 10 \mathrm{~Hz}), 152.98(\mathrm{~d}, J(\mathrm{C}, \mathrm{P})=3 \mathrm{~Hz})$ ppm; IR (KBr): v = 2983, 2931, 2903, 2855, 1603, 1394, 1243, 1130, 1052, 1020, 964, 759, $670 \mathrm{~cm}^{-1}$

\section{Tetrakis-1,3,5,7-(4-phosphonatophenyl)adamantane:}

tetrakis-1,3,5,7-(4diethylphosphonatophenyl)adamantane $(1.7 \mathrm{~g}, 1.73 \mathrm{mmol})$ was placed in a round bottom flask and concentrated aqueous solution of hydrogen chloride $(150 \mathrm{~mL})$ was added. The mixture was refluxed with vigorous stirring overnight and cooled. A white precipitate was filtered off and quickly transferred to a round bottom flask and dried under high vacuum for $72 \mathrm{~h}$. Yield $1.2 \mathrm{~g}(93 \%)$ of a white slightly hygroscopic powder. ${ }^{1} \mathrm{H}$ NMR (400 MHz, DMSO- $\left.d_{6}\right): \delta=2.1$ (br s, 12H); $7.6(\mathrm{~m}, 16 \mathrm{H})$ ppm; ${ }^{31} \mathrm{P}$ NMR (101 MHz, DMSO-d $) 12$ (s) ppm; IR (KBr): v = 3448. $2923,2898,2852,1604,1500,1444,1396,1138,999,929,827,704,559,490 \mathrm{~cm}^{-1} . \mathrm{CH}$ elemental analysis for $\mathrm{C}_{34} \mathrm{H}_{36} \mathrm{O}_{12} \mathrm{P}_{4}$ - experimental (calculated): $\mathrm{C}-58.69$ (58.89), $\mathrm{H}-4.04$ (4.24).

Tetrakis-1,3,5,7-(4-phosphonophenyl)adamantane-V hybrid material (TPPhA-V): Tetrakis1,3,5,7-(4-phosphonatophenyl)adamantane $(0.8 \mathrm{~g}, 1.05 \mathrm{mmol})$ was dissolved in dry DMSO $(20 \mathrm{~mL})$ with stirring and neat Vanadium(V) oxytriisopropoxide $(0.96 \mathrm{~mL}, 4.07 \mathrm{mmol})$ was added to this solution dropwise. Immediately solution turns orange and the reaction mixture was left stirred for three days. The green jelly-like precipitate was separated by centrifugation, thoroughly washed with $\mathrm{H}_{2} \mathrm{O}, \mathrm{EtOH}, \mathrm{Et}_{2} \mathrm{O}$ and dried under high vacuum for $10 \mathrm{~h}$ yielding 0.79 
g $(62.5 \%)$ of TPPhA-V. IR (KBr): $v=3008,2921,2900,2850,1635,1604,1500,1429$, 1398, 1138, 1028, 993, 953, 831, 789, 708, 576, $494 \mathrm{~cm}^{-1}$. CHP elemental analysis for $\mathrm{C}_{34} \mathrm{H}_{28} \mathrm{O}_{16} \mathrm{P}_{4} \mathrm{~V}_{4} \bullet 10 \mathrm{H}_{2} \mathrm{O}$ - experimental (calculated): $\mathrm{C}-32.49$ (34.03), $\mathrm{H}-4.76$ (4.03), $\mathrm{P}-9.9$ (10.32). The amount of hydrated water was determined by TGA - 15\%. Ratio of V:P by EDS was $1.20 \pm 0.07$ for an average of three measurements.

In a typical catalytic reaction a $15 \mathrm{~mL}$ Ace Glass pressure tube was loaded with $1 \mathrm{mmol}$ of benzylic alcohol, $0.02 \mathrm{~g}(0.017 \mathrm{mmol})$ of TPPhA-V and $1 \mathrm{ml}$ of toluene. Oxygen was added to a pressure of $2 \mathrm{~atm}$, and the pressure tube was placed in an oil bath thermostated at $100^{\circ} \mathrm{C}$. After 15 hrs the glass pressure tube was removed from the oil bath, cooled to room temperature and then analyzed by gas chromatography using a Hewlett-Packard 6980 GC apparatus equipped with a Restek Rtx-5MS column $(30 \mathrm{~m} \times 0.32 \mathrm{~mm}$ with a $0.25 \mu \mathrm{m}$ coating. 